\title{
School District Interests and Challenges Buying Chicken Raised without Antibiotics
}

\author{
Kathryn J. A. Colasanti ${ }^{1}$, Laura Stanley ${ }^{2}$, Michael W. Hamm ${ }^{1}$, Kathy Lawrence ${ }^{2}$ \\ ${ }^{1}$ Center for Regional Food Systems, Michigan State University, East Lansing, MI, USA; ${ }^{2}$ School Food FOCUS, Public Health Solu- \\ tions, New York, NY, USA. \\ Email: colokat@msu.edu
}

Received August $11^{\text {th }}, 2013$; revised September 11 ${ }^{\text {th }}, 2013$; accepted September $18^{\text {th }}, 2013$

Copyright (C 2013 Kathryn J. A. Colasanti et al. This is an open access article distributed under the Creative Commons Attribution License, which permits unrestricted use, distribution, and reproduction in any medium, provided the original work is properly cited.

\begin{abstract}
The overuse of antibiotics in animal agriculture is recognized as contributing to human antibiotic resistance. With large meat purchases, particularly chicken, school districts have an opportunity to leverage their buying power to engage with this issue. However, few school food service professionals have done so and little is known about their awareness, attitudes, or experiences. This research surveyed 36 school districts affiliated with School Food FOCUS, which works on procurement reform with many of the largest school districts in the country. Questions were designed to solicit familiarity with the issue of antibiotic use in poultry production, attitudes, and extent of relevant action taken. Motivations and barriers for purchasing poultry raised with minimal, safe and sustainable use of antibiotics as well as fresh (raw) poultry, which has been found to be an affordable way to menu antibiotic-free chicken, were assessed. Results revealed that this issue is important to respondents but difficult to address due to more immediate concerns. Barriers are experienced with purchasing both chicken raised without antibiotics and preparing fresh chicken. Product cost was perceived as a particularly high barrier. Responding to concerns of parents and the community was a top motivation.
\end{abstract}

Keywords: School Meals; School Lunch; Antibiotics; Public Health Initiatives

\section{Introduction}

\subsection{Antibiotic Overuse}

Alarms noting the connection between antibiotic misuse and overuse in agricultural production and its effect on the rise of antibiotic-resistant infections have been sounding for decades [1-4]. Research has affirmed that the use of vast quantities of antibiotics in animal production clearly exceeds the amounts used in human medicine [2,5] and contributes to the presence of antibiotic resistant bacteria in animals and the environment [6]. Many antibiotics given to livestock are the same as those used in human medicine, but are available over the counter without a prescription for use in healthy food animals. As antibiotic resistant pathogens evolve, they move into the environment, leading to situations in which previously treatable bacterial illnesses in humans no longer respond to prescribed medications [2,3,7-10]. Many major public health and consumer groups have called for significant reforms in policy regulating the use of antibiotics in animal production, including the virtual elimination of antibiotics for non-medical uses, such as growth promotion, in animals [11].

\subsection{The Link with Schools}

While the public health concern with antibiotic overuse continues to grow and interest in healthy and sustainable school meals has attracted significant public attention in recent years, the two issues have seldom been brought together. Literature broadly discussing food system reforms occasionally addresses both the need to improve school food and the overuse of antibiotics but does not draw a connection between the two issues $[12,13]$ or does so only in passing[14]. The only literature known by the authors to connect school food service staff perceptions with the use of antibiotics found that respondents frequently and mistakenly associated "no antibiotics and/or growth hormones" with "organic" [15]. Literature on efforts to improve school food, including farm to school, often discusses health impacts and sustainability but not in relation to antibiotic use [16-20].

Given the significant buying power of school food programs and the public health mission of school meals, 
schools would seem to be a natural partner in the effort to combat the non-therapeutic use of antibiotics through purchasing commitments. The paucity of literature in this area presents a critical need to understand not only the landscape of awareness and attitudes towards agricultural antibiotic use but also the motivations and barriers food service directors experience in sourcing meat and poultry raised entirely without antibiotics or with minimal, safe and sustainable (MSS) use of antibiotics.

School Food FOCUS, a program of Public Health Solutions, is a national collaborative based in New York City, USA that leverages the knowledge and procurement power of large school districts to make school meals nationwide more healthful, regionally sourced, and sustainably produced. Launched in late 2008 with seed funding from the W.K. Kellogg Foundation, FOCUS works with food service professionals and their community partners to collect, analyze, and use food system research to spur change in procurement methods in school meal programs. FOCUS currently works with 36 districts (32 at the time of this survey), which collectively represent more than 4.3 million children.

\subsection{Study Aims}

Based on interest from one its member districts, Chicago Public Schools, FOCUS began to investigate options to source poultry raised without the non-therapeutic use of antibiotics for school meals. While working in depth with Chicago, FOCUS and Michigan State University collaborated to survey FOCUS member and affiliated school districts. By addressing the critical literature gap in this area, the researchers hoped not only to determine a baseline of current interest levels and purchasing practices but also to pave the way for an even larger and more effective public health initiative to reduce purchases of meat produced with an overuse of antibiotics in institutional food service programs. The popularity of chicken entrées, which are menued on a near daily basis in schools, made chicken a natural choice for beginning this investigation.

This research asked:

- What is the familiarity level with the issue of antibiotic use in poultry production, the attitude towards the issue, and the extent of action food service directors are taking or prepared to take?

- What are food service directors' primary motivations in sourcing poultry raised with no or minimal antibiotics?

- What are the primary barriers they face?

For the purposes of the survey, chicken raised with "minimal, safe and sustainable use of antibiotics" (MSS chicken) was defined as chicken labeled "antibiotic free" or grown in compliance with a protocol that strictly limits antibiotic use. Because antibiotic-free poultry is at this time most affordable for schools in a raw or frozen-raw form, questions about purchasing and preparing raw chicken were also included.

\section{Methods}

\subsection{Subjects}

This research targeted 36 school districts belonging to or informally affiliated with the FOCUS network. These districts are distributed across the US. All districts in this sample had at least 40,000 students in their district; the largest had 1.1 million students. Though not representative of all school food service directors nationally, they represent many of the very largest school districts in the country. Because of their size, they also represent some of the most concentrated buying power in school food service and, therefore, great potential to shift industry practices based on the purchasing demands they make. This research was approved by the Michigan State University Human Research Protection Program as part of a larger study on July 1, 2008 (IRB\#x08-645).

\subsection{Instruments}

An electronic survey instrument consisting of 17 questions was developed through Qualtrics ${ }^{\mathrm{TM}}$ software (Qualtrics Labs, Inc.). Three questions asked about school district demographics; two asked about participation in FOCUS events offering education about antibiotic use; and two asked about purchasing of raw chicken and MSS chicken. Seven questions asked about awareness, attitudes, motivations, and barriers on a 5-point Likert-type scale. "I don't know" was used as the mid-point response on these questions.

Two open-ended questions gave respondents a chance to comment on why they thought reducing antibiotic use in the production of chicken sold to school food service was important or unimportant (prompt varied according to their previous response) and to comment on their experience purchasing or attempting to purchase MSS chicken. A final question allowed respondents to request additional information if desired. The survey was anonymous unless this question was answered. Prior to releasing the survey, the instrument was pilot-tested for clarity; validity of responses was generated with ten food service directors external to the survey sample and adjusted according to their feedback.

\subsection{Procedure}

A hyperlinked URL to the survey was emailed directly to food service directors from Michigan State University in November 2011, along with a brief note describing the purpose and content of the survey. During the two months in which responses were collected, three email 
reminders were sent, including one from a food service director who had completed the survey early. Additionally, all food service directors in the target population who had not indicated their completion of the survey received a reminder phone call in mid-late December. All surveys were completed electronically.

\subsection{Analysis}

Data was analyzed using the SPSS 19.0 statistical package (IBM Corporation, Somers, NY, 2010). The analysis relied on descriptive statistics - namely means, ranges, and frequencies. Cross-tabulations were performed in order to explore relationships between variables. Where responses to open-ended questions provided new insights, comments are reported verbatim. Due to the small sample size, tests of statistical significance were not conducted.

\section{Results}

\subsection{School District Characteristics}

Of the 36 districts surveyed, 16 provided substantially complete survey responses, for a response rate of 44 percent. The school districts represented in the survey served between 12,000 and 256,000 breakfasts each day, for an average of 49,420, and between 26,000 and 741,000 lunches each day, for an average of 130,756. Two responding districts also served dinner, 10,000 and 100,000 per day respectively.

The 14 respondents who gave an estimate of the total pounds of chicken purchased in the 2010-2011 school year collectively represent 21.1 million pounds of annual demand for chicken from USDA Foods and 2.8 million pounds of annual demand for chicken purchased on the open market. Five of the school districts only purchased chicken through USDA Foods. One district purchased chicken on the open market only.

Four school districts participated in a breakout session on antibiotic use in poultry at the School Food FOCUS 2011 annual gathering in Denver, Colorado, whether it was someone on the school food service staff $(n=3)$ or the individual completing the survey $(\mathrm{n}=1)$. Of these, two districts also participated in a FOCUS webinar on antibiotic use in poultry held on September 21, 2011 or subsequently listened to the recording. Four additional districts also participated in the webinar or later watched a recording. Altogether, eight of the 16 school districts responding had some prior exposure to the issue of antibiotic use through one of these two venues hosted by FOCUS.

\subsection{Importance of MSS Chicken}

While $88 \%$ of respondents said that reducing antibiotic use in the production of chicken sold to school food service is either very important (38\%) or somewhat important (50\%), only $38 \%$ said that it was a very high (13\%) or somewhat high (25\%) priority, given other, more immediate pressures they face in serving wholesome food that is highly affordable and meets strict USDA standards for nutritional content and portion sizing. The majority of school districts (56\%) indicated they were not equipped to prepare raw poultry, even if that was the only way in which to introduce MSS chicken.

Cross-tabulations showed that there were no strong correlations between how important respondents thought reducing antibiotic use was and how interested they were in preparing raw chicken, with the six respondents saying the issue was very important split between saying they were not at all $(\mathrm{n}=2)$ or not very $(\mathrm{n}=1)$ interested in sourcing raw chicken and saying they were very interested $(n=3)$.

The districts that had participated in educational opportunities (the conference breakout session, the webinar, or both) and the districts that had not participated showed similar awareness and attitudes. Participating and nonparticipating districts reported comparable mean familiarity levels (4.25 and 4.0 respectively) on a five point Likert-type scale, comparable mean importance of the issue of reducing antibiotic use (4.13 and 4.13), and comparable mean priority level of reducing antibiotic use (3.0 and 3.13). (See Figure 1.)

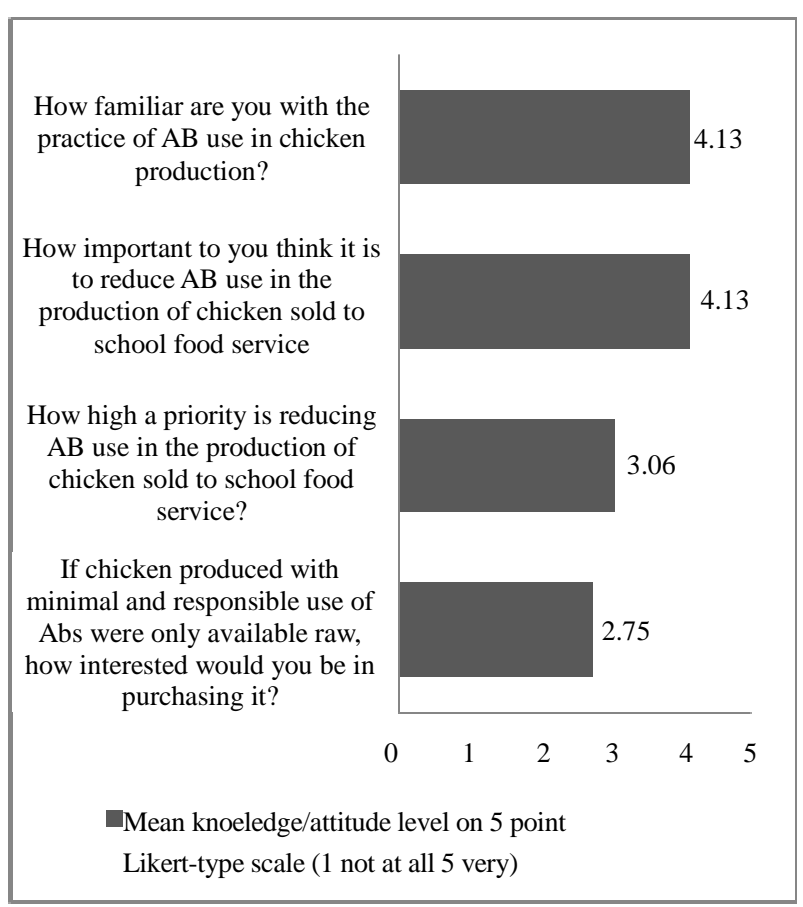

Figure 1. Comparison of mean knowledge of/attitudes towards chicken produced with minimal, safe and sustainable use of antibiotics (ABs) and mean interest in sourcing raw chicken $(\mathbf{n}=16)$. 


\subsection{Motivations and Concerns}

With regards to the three surveyed factors that motivate or would motivate purchases of MSS chicken, responding to the concerns of families, communities, and/or the general public (mean of 4.31) and reducing antibiotic resistance (mean of 4.25) received noticeably higher rankings on a five point Likert-type scale ( 5 being very important, 1 being not at all important) than did improving animal welfare (mean of 3.75).

When given an open-ended question regarding why the issue of antibiotic use was important, these three concerns were all mentioned, as well as a general mention of health and a desire for "natural products," also expressed as a desire for food "to be delivered in it's [sic] purest state." When those who responded that they thought reducing antibiotic use was either not very or not at all important were given an open-ended question as to why, two people shared doubts, one regarding the animal welfare concern ("I believe that are [sic] some good reasons for using antibiotics in poultry") and one regarding the health concern ("I do not think it has been shown to adversely affect students.”).

\subsection{Barriers}

The most highly ranked barrier to sourcing MSS chicken was product cost, with nearly three-quarters of respondents indicating this was very much $(27 \%)$ or somewhat of a barrier (47\%). The ability to verify vendor or producer claims about the use of antibiotics and the ability to find new vendors with the product were also highly ranked barriers.

The barriers to purchasing raw (frozen or fresh) chicken and cooking it from scratch overall received slightly lower rankings than the aforementioned barriers. (See Figure 2.) The availability of labor (mean of 4.00) and of labor with adequate training (mean of 3.81) were the most highly ranked barriers. Whether kitchen infrastructure presented impediments was nearly an even split among respondents: $56 \%$ found space to be somewhat or very much a barrier; $50 \%$ each found equipment and storage to be somewhat or very much a barrier. When given the chance to rank and describe other barriers, two respondents wrote in that food safety risk was very much a barrier.

Looking across the cases at the total average barrier ranking, as well as the average infrastructure (availability of space, equipment, and storage) barrier rankings and the average labor rankings (availability of labor and labor with adequate training) indicates that school districts experience similar barrier levels across these categories. Cross-tabulations indicate no apparent relationship

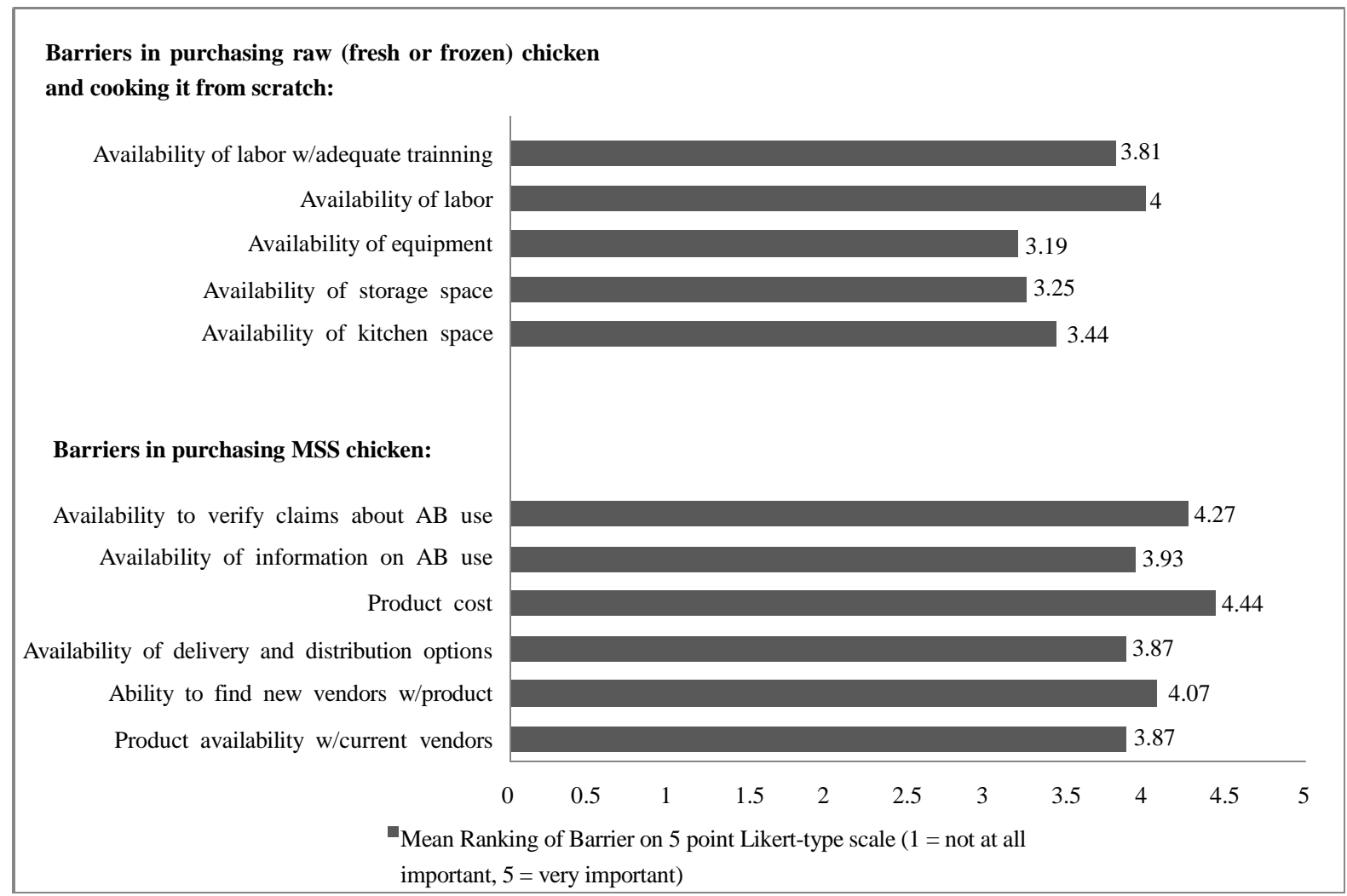

Figure 2. Comparison of mean rankings of barriers to purchasing raw chicken and chicken produced with minimal, safe and sustainable (MSS Chicken) use of antibiotics (ABs) $(n=16)$. 
between the size of a school district (as indicated by the total quantity of chicken purchased annually) and the degree of barriers experienced.

\subsection{Current Purchases}

Respondents shared both whether they werepurchasing MSS chicken and the extent to which they werebringing in raw chicken. Nearly a third (31\%) werecurrently purchasing MSS chicken; an additional twenty-five percent werelooking for sources. The five food service directors who werecurrently making purchases indicated they would be buying between 4,000 and 600,000 pounds for the 2011-2012 school year.

Eleven of the 16 respondents never utilized raw chicken in any of their schools. One district never used raw chicken in their elementary schools but did so monthly in their middle and high schools. Two districts prepared fresh chicken less than once a month in elementary, middle, and high schools and two districts prepared raw chicken two to three times per month across all grade levels.

\section{Discussion}

The issue of antibiotic use in poultry production is clearly important to the vast majority of the food service directors surveyed. However, the issue is not of the highest priority for most of them. This is likely a reflection of the myriad more immediately pressing concerns food service directors face in navigating changing federal nutrition standards, student preferences, rising food costs, tight food budgets, and ever-growing demands from parents and the public.

In this context, food service directors may be more likely to prioritize food safety and nutritional concerns, areas where reforms have more immediate and tangible impacts. This is perhaps the point of view of the respondent who commented that antibiotics have not "been shown to adversely affect students." While making changes that impact the broader landscape of public health and the environment may be of interest, food service directors may feel they lack the capacity to take a stand on such a complex societal issue.

The barriers experienced likely also impacted the priority level assigned to the issue of antibiotic use. Barriers to purchasing both MSS chicken and raw chicken were all fairly high. Even the lowest ranked barrier, availability of equipment to prepare raw chicken (mean of 3.2), was above the midpoint, represented by "do not know." The results indicate that the barriers food service directors experience in purchasing MSS chicken, which overall have higher mean rankings, may contribute more to the discrepancy between the degree of importance and the priority level assigned to this issue than do the barri- ers to preparing raw chicken. That said, the interest in purchasing raw chicken was relatively low. Apparently the barriers to preparing raw chicken, with the availability of adequate labor topping the list, were sufficient to result in only just over $40 \%$ of respondents stating they were very (25\%) or somewhat (19\%) interested in sourcing raw poultry.

The fact that responding to concerns of families, communities, or the general public was the most highly ranked motivation for purchasing MSS chicken, alongside the relatively low priority level respondents assign this issue, may indicate that few food service directors were hearing from their communities about this issue.

\section{Limitations}

It is possible that the FOCUS member and affiliated school districts that were more familiar with or interested in the issue of antibiotic use in poultry production were more likely to respond to the survey. It is also possible that the individual completing the survey, which could have been a different person than the person to whom the survey link was initially sent, had incomplete information about their school district's circumstances or held views that were not representative of school food service leadership. Lastly, the small sample size of this survey as well as the distinct characteristics of the survey population, who are among the largest school districts in the country, mean these results are not generalizable to the larger national population of school food service directors. However, the results provide a baseline for further research with this broader population.

\section{Conclusions}

These survey results offer new insights into previously unexplored areas: food service director perspectives on chicken raised with minimal, safe and sustainable use of antibiotics and motivations and barriers to source both chicken produced according to such standards and fresh chicken in general. The overarching message from the results is that food service directors are interested in sourcing chicken raised according to a strict protocol of antibiotic use, but face numerous challenges in doing so.

The research points to a need to work with food service directors to overcome the barriers they face in sourcing MSS chicken. Several areas in which this can be done are evident from the results. First, given the prevalence with which respondents felt that cost was a barrier to source MSS chicken, it will be important for advocates to encourage market development for more competitively priced options, both fresh and further processed. FOCUS' experience working with Chicago Public Schools indicates that such opportunities are already available if the district is willing and able to pur- 
chase fresh poultry [21]. Second, in order to help schools verify claims about antibiotic use, advocates could assist schools in developing purchasing agreements that allow for verification, [e.g. 22-24], as well as push for policy that more strictly regulates antibiotic usage. Finally, noting the weight given to concerns from parents and the community, advocates could engage these constituencies to empower them to speak out in support of food service efforts to "buy sustainable."

In light of the large body of evidence demonstrating the danger that overuse of antibiotics in animal agriculture poses to people and children in particular, [25-27] some districts may increasingly feel they have a responsibility to, within their capacity, move away from poultry produced with the non-therapeutic use of antibiotics. As Weaver-Hightower notes, "food production practices implicate schools in environmental degradation and animal cruelties...[and]...schools teach children - whether explicitly or implicitly—to ignore, accept, or resist” (p. 18) such questionable practices [14]. This research argues that society has an even greater responsibility to help schools overcome their limitations in order to reach this end. While school district sourcing of chicken raised with minimal, safe and sustainable use of antibiotics has generally not been at the top of the agenda for either school food or public health advocates, it appears to be a natural fit in both camps and school food service directors in some of the largest, most influential districts appear to be eager to listen.

Drawing from this baseline research, FOCUS has since engaged 15 of its member districts in its new National Procurement Initiative (NPI), which involves an effort to develop specifications for fresh and processed chicken products that will include MSS antibiotic standards. Since the launch of this project in November 2012, interest in purchasing fresh and MSS poultry appears to have intensified. FOCUS is aware of four districts that have initiated purchasing of fresh, local poultry raised without antibiotics for the current school year (2013-2014). One of these newcomers, Jefferson County Public Schools (Colorado, USA) is buying and serving chicken raised without antibiotics on a monthly basis, representing volumes second only to the RWA purchases of Chicago Public Schools. As NPI specifications are finalized and then utilized by schools, there is an opportunity to track both how school district interest and motivations change and the extent to which initiatives like these help overcome barriers.

\section{Acknowledgements}

The authors wish to thank colleagues at School Food FOCUS, the Michigan State University Center for Regional Food Systems and Chartwells Chicago for their input into this research and manuscript and the W.K.
Kellogg Foundation for funding support.

\section{REFERENCES}

[1] S. B. Levy, "The Challenge of Antibiotic Resistance," Scientific American, Vol. 278, 1998, pp. 46-53. http://dx.doi.org/10.1038/scientificamerican0398-46

[2] W. Witte, "Medical Consequences of Antibiotic Use in Agriculture,” Science, Vol. 279, No. 5353, 1998, pp. 996997. http://dx.doi.org/10.1126/science.279.5353.996

[3] M. Cohen and R. Tauxe, "Drug-Resistant Salmonella in the United States: An Epidemiologic Perspective," Science, Vol. 234, No. 4779, 1986, pp. 964-969. http://dx.doi.org/10.1126/science.3535069

[4] Swann Committee, "Report of Joint Committee on the Use of Antibiotics in Animal Husbandry and Veterinary Medicine,” Her Majesty’s Stationary Office, London, 1969.

[5] M. Mellon, C. Benbrook and K. L. Benbrook, "Hogging It: Estimates of Antimicrobial Abuse in Livestock," 2001. http://www.ucsusa.org/food_and_agriculture/science_and _impacts/impacts_industrial_agriculture/hogging-it-estim ates-of.html

[6] W. Witte, "Selective Pressure by Antibiotic Use in Livestock," International Journal of Antimicrobial Agents, Vol. 16, No. S1, 2000, pp. S19-S24. http://dx.doi.org/10.1016/S0924-8579(00)00301-0

[7] F. J. Angulo, O. E. Heuer, A. M. Hammerum, P. Collignon and H. C. Wegener, "Human Health Hazard from Antimicrobial-Resistant Enterococci in Animals and Food," Clinical Infectious Diseases, Vol. 43, No. 7, 2006, pp. 911916. http://dx.doi.org/10.1086/507534

[8] H. C. Neu, “The Crisis in Antibiotic Resistance," Science, Vol. 257, No. 5073, 1992, pp. 1064-1073. http://dx.doi.org/10.1126/science.257.5073.1064

[9] T. F. O’Brien, J. D. Hopkins, E. S. Gilleece, A. A. Medeiros, R. L. Kent, B. O. Blackburn, et al., "Molecular Epidemiology of Antibiotic Resistance in Salmonella from Animals and Human Beings in the United States," New England Journal of Medicine, Vol. 307, No. 1, 1982, pp. 1-6. http://dx.doi.org/10.1056/NEJM198207013070101

[10] K. E. Smith, J. M. Besser, C. W. Hedberg, F. T. Leano, J. B. Bender, J. H. Wicklund, et al., "Quinolone-Resistant Campylobacter Jejuni Infections in Minnesota, 1992-1998," New England Journal of Medicine, Vol. 340, No. 20, 1999, pp. 1525-1532. http://dx.doi.org/10.1056/NEJM199905203402001

[11] J. Wenderoff, "58 Health and Consumer Groups Tell FDA to Close Loopholes in Antibiotic Guidelines,” 2012. http://www.pewhealth.org/reports-analysis/issue-briefs/58 -health-and-consumer-groups-tell-fda-to-close-loopholesin-antibiotic-guidelines-85899406575

[12] M. Muller, A. Tagtow, S. L. Roberts and E. MacDougall, "Aligning Food Systems Policies to Advance Public Health,” Journal of Hunger \& Environmental Nutrition, Vol. 4, No. 3-4, 2009, pp. 225-240. http://dx.doi.org/10.1080/19320240903321193

[13] C. Cannuscio and K. Glanz, "Food Environments,” In: A. L. Dannenberg, H. Frumkin and R. J. Jackson, Eds., Mak- 
ing Healthy Places: Designing and Building for Health, Well-Being and Sustainability, Island Press/Center for Resource Economics, Washington DC, 2011, pp. 50-62.

[14] M. B. Weaver-Hightower, "Why Education Researchers Should Take School Food Seriously," Educational Researcher, Vol. 40, No. 1, 2011, pp. 15-21. http://dx.doi.org/10.3102/0013189X10397043

[15] S. DeBlieck, C. H. Strohbehn, T. L. Clapp and N. Levandowski, "Building Food Service Staff Familiarity with Local Food,” Journal of Hunger \& Environmental Nutrition, Vol. 5, No. 2, 2010, pp. 191-201. http://dx.doi.org/10.1080/19320241003800318

[16] M. Story, K. M. Kaphingst and S. French, "The Role of Schools in Obesity Prevention," The Future of Children, Vol. 16, No. 1, 2006, pp. 109-142. http://dx.doi.org/10.1353/foc.2006.0007

[17] M. Vallianatos, R. Gottlieb and M. A. Haase, "Farm-toSchool: Strategies for Urban Health, Combating Sprawl, and Establishing a Community Food Systems Approach,” Journal of Planning Education and Research, Vol. 23, No. 4, 2004, pp. 414-423. http://dx.doi.org/10.1177/0739456X04264765

[18] A. Winson, "School Food Environments and the Obesity Issue: Content, Structural Determinants, and Agency in Canadian High Schools,” Agriculture and Human Values, Vol. 25, No. 4, 2008, pp. 499-511. http://dx.doi.org/10.1007/s10460-008-9139-8

[19] L. Carlsson and P. L. Williams, "New Approaches to the Health Promoting School: Participation in Sustainable Food Systems," Journal of Hunger \& Environmental Nutrition, Vol. 3, No. 4, 2008, pp. 400-417. http://dx.doi.org/10.1080/19320240802529243

[20] M. Vallianatos, "Healthy School Food Policies: A Check- list,” 2002

http://scholar.oxy.edu/cgi/viewcontent.cgi?article=1392\& context=uep_faculty

[21] L. Stanley, K. Colasanti and D. Conner, “A 'Real Chicken' Revolution: How Two Large Districts are Shifting the School Poultry Paradigm with Scratch Cooking," Childhood Obesity, Vol. 8, No. 4, 2012, pp. 343-346.

[22] Health Care without Harm, "Sample Procurement Policy: Purchasing Meat, Poultry, Dairy and Seafood Produced without Inappropriate Antibiotic Use,” 2004.

http://www.iatp.org/documents/sample-procurement-polic y-purchasing-meat-poultry-dairy-and-seafood-producedwithout-ina-0

[23] School Food FOCUS, "Purchasing Guidelines that Minimize the Use of Antibiotics in Poultry Production,” 2011. http://www.schoolfoodfocus.org/site/wp-content/uploads/ 2011/10/HHIF-FOCUS-chicken-RFP-10.31.11.pdf

[24] Humane Farm Animal Care, "Humane Farm Animal Care Animal Care Standards: Chickens,” 2009. http://www.certifiedhumane.org/uploads/pdf/Standards/E nglish/Std09.Chickens.2J.pdf

[25] R. L. Goforth and C. R. Goforth, “Appropriate Regulation of Antibiotics in Livestock Feed," Boston College Environmental Affairs Law Review, Vol. 28, No. 1, 2000, pp. 39-77.

[26] United States General Accounting Office, “Antibiotic Resistance: Federal Agencies Need to Better Focus Efforts to Address Risk to Humans from Antibiotic Use in Animals,” 2004. http://www.gao.gov/assets/250/242186.pdf

[27] “Joint FAO/OIE/WHO Expert Workshop on Non-Human Antimicrobial Usage and Antimicrobial Resistance: Scientific assessment,” 2003.

http://www.who.int/foodsafety/publications/micro/en/amr.pdf 